\title{
Relation of the Number of Public Health Nurses Employed by Municipal Governments to Health Care Programs
}

\author{
Toshiyuki Ojima
}

\begin{abstract}
To refer to municipal governments employing public health nurses (PHNs), the relationship between the number of PHNs and accomplishment in health care programs was observed. Data regarding accomplishment in health care programs were obtained by a nationwide questionnaire survey sent to all of the municipal governments (cities, towns, and villages). Of the 3,268 governments, 2,800 ones or $86 \%$ responded the survey. Population sizes and standardized mortality ratios for major causes of death of municipalities were obtained from the Wide-area Information-exchange System for Health and welfare administration (WISH). Results were as follows: The correlation coefficient between the ratios of PHNs and participation rates to stomach cancer examination was 0.63. The correlations were significant and strong in the program achievement of the following; tracking of non-examinees, registration of stroke patients, activities of local community organizations, participation rates to basic health examination, stomach cancer examination, cervical cancer examination, health education, health counseling, and rehabilitation programs. The results suggest that the number of PHNs in a municipality is one of the important factors to obtain effective achievement of health care programs. Using regression models the author estimated that 1.96-2.72 PHNs per 10,000 population are required to achieve the target participation rates organized by the Japanese Government. J Epidemiol, $1994 ; 4: 121-128$.
\end{abstract}

public health nurses, health manpower, health care programs, municipal governments, Wide-area Information-exchange System for Health and welfare administration (WISH)

The Ministry of Health and Welfare of the Japanese government takes charge of health services on the national level. Under the national government, 47 prefectural governments including Tokyo metropolitan government take charge of local health services. Public health centers established for every 100,000 population as standard by prefectural governments, therefore, provide technical support on local activities of health services. Under the prefectural governments, municipal governments such as cities, towns, and villages are responsible for providing various aspects of personal health services.

The public health centers played leading part in providing personal health services, and the municipal governments supported them till a decade ago. Nowadays, the municipal governments are thought to be the best organizations to provide the health services for citizens because of accessibility. In Japan there were 850 public health centers $^{1)}$ and 3,268 municipal governments, which were 655 cities, 2,003 towns, 587 villages, and 23 special wards in Tokyo $^{2)}$, in March 1991.

In 1983, the Law of Health Care for the Aged was legislated and various health-related programs, such as prevention, medical treatment, and rehabilitation programs related to geriatric diseases, started to be conducted systematically. To carry out these programs effectively, public health nurses (PHNs) have been assigned to most of the municipal governments. Sakata ${ }^{3)}$ observed the relationship between the participation rates in health examinations and the methods of implementation of examination programs based on surveys on health care programs in the municipal governments, and showed a significant relation to cooperation by local community organizations and simultaneous implementation of multiple health examinations. Tatara and his colleagues ${ }^{4)}$, on the other hand, observed the relation between achievement of health care programs (participation rates of health examinations and

Received December 24, 1993 ; accepted August 12, 1994.

Department of Public Health, Jichi Medical School, Tochigi, Japan.

Address for correspondence: Department of Public Health, Jichi Medical School, 3311-1 Yakushiji Minamikawachi-machi Tochigi, 329-04 Japan. 
other programs) and the numbers of PHNs (the total numbers of those assigned to prefectural public health centers and those affiliated with municipal governments) per unit population, using a prefectural public health center area as a unit. They showed that there was definitely positive correlation between the two.

Thus, the numbers of PHNs in an area is one of the important factors of health care activities. To reveal the relationship between the numbers of PHNs in the municipal governments and achievement of health care programs according to the Law of Health Care for the Aged, a nationwide mail survey was conducted in 1991. The results of the study are expected to provide valuable data for determining the optimum numbers of PHNs for these municipal governments. The unique features of the study are: (1) the statistics for the entire country were collected in the municipal government units; and (2) a wide variety of indices (including systems of implementation of programs) were used for the analyses.

\section{MATERIALS AND METHODS}

\section{Data obtain}

As a part of the "Study on health care programs in the secondary medical service areas"5) (chairperson; Atsuhiko Tsukuda, M.D.) by the Health Policy Survey and Research Project supported by the Health Science Research Fund of the Ministry of Health and Welfare, I conducted a survey on health care programs and took charge of planning and analysis of the portion related to the present study. The survey was conducted from January through March 1991. A questionnaire including 500 items concerning health care programs conducted by municipal governments were mailed out to persons in charge of health services for all of the 3,268 municipal governments (including special wards in Tokyo metropolitan) throughout Japan. Among the survey items, those concerning achievement in the health care programs and specific approaches taken in these programs (arrangement for public participation in health examinations and handling of data following the examinations) were used for the present study. Of the 3,268 municipalities, 2,800 or $85.7 \%$ governments responded.

The Statistical Information Division, the Secretariat of the Ministry of Health and Welfare offers a information system called WISH (Wide-area Information-exchange System for Health and welfare administration) ${ }^{6}$ to each prefectural government and its public health centers. I used a subsystem of WISH, "Regional Health Planning Support System", with the cooperation of Department of Health, Prefectural Government of Aichi. I obtained information of the population for each age group, standard mortality ratios (SMRs) for major causes of death, and the numbers of participants for health examinations for each municipal government as well. For the numbers of
PHNs, the data from the Planning Section, Health Policy Bureau, Ministry of Health and Welfare were used.

These data were linked and then analyzed by using $\mathrm{SAS}^{7-9)}$, a software of general statistical package for personal computers.

\section{Data arrangement}

Data items used in this study are shown in Table 1.

For the numbers of PHNs, the numbers per 10,000 population were used ( abbreviated to "ratios of PHNs"). For the calculation of means and correlation and regression coefficients, normal logarithms were used. Eighty or 2.9\% municipalities without PHNs were treated as missing values.

The ratios of PHNs were also analyzed after conversion to categorical indices ; $2+$ per 10,000 population and $<2$, which were based on the national mean.

Categorical indices are obtained from the mail survey above-mentioned.

Quantitative indices were converted to normal loga-

Table 1. A List of the data analyzed in the study.

Independent Variable

Ratio of $\mathrm{PHN \textrm {s }}$

(The Number of PHNs per population 10,000)

Target Variables

Quantitative Indices

[Indices on Health Examination]

1. Participation Rate to Basic Health Examination

2. Participation Rate to Stomach Cancer Examination

3. Participation Rate to Cervical Cancer Examination

[Indices on Other Health Programs]

4. Participation Rate to Health Education

5. Participation Rate to Health Counseling

6. Participation Rate to Rehabilitation Programs

[Indices of Mortality]

7. SMR of Malignant Neoplasms

8. SMR of CVDs (Cerebro-Vascular Diseases)

Categorical Indices

[Indices on Examination System]

1. Tracking of Non-Examinees

2. Tracking of Non-Respondents to Examinees

Required taking Detailed Examinations

3. Individual Invitation to Receive Examinations

[Indices on Other Health Programs]

4. Buses providing transportation

to Rehabilitation Programs

5. Registration of Stroke Patients

6. Activities of Local Community Organizations Stratification Indices

1. Population Size

2. Ratio of Physicians

(The Number of Physicians per Population 1,000)

Notes : abbreviated to the parts in italics in following tables. 
rithms, since that would conform to a normal distribution and rationalize the calculations with correlation and regression coefficients.

The subject numbers of health examinations in population should be bound to except the people under medical services and health examinations on employment. However, the actual numbers of subject cannot be assessed at present. Therefore I calculated participation rates in terms of the numbers of participants divided by the target age populations.

Quantitative indices were also used as 2 categorical indices; "high" and "low". The indices were categorized as follows: participation rates were categorized according to the target participation rates (the target participation numbers of examinees specified in the Second 5-year Plan of the Health Program for the Aged ${ }^{10)}$ divided by the target age population). The critical points used were $35 \%$ for basic health examination, $21 \%$ for stomach cancer examination, and $24.8 \%$ for cervical cancer examination. The achievement of other health care programs were categorized according to the basis of the national mean participation rates by a target population (the national total numbers of participants ${ }^{11)}$ divided by the national population aged 40 years or older ${ }^{12)}$ ). Namely, the critical points were $19 \%$ for health education, $18 \%$ for health counseling, and $0.15 \%$ for rehabilitation programs. SMRs were divided into two groups; $1+$ and $<1$.

The population size of municipality was divided into 3 levels for stratification analyses ; $<10,000$ (small), 10,00049,999 (medium), and 50,000+ (large).

The numbers of physicians per 1,000 population (abbreviated to "ratios of physicians") were categorized based on $<1$ and $1+$.

\section{Statistical analyses}

Pearson's correlation coefficients were used to observe relationships between two quantitative data.

For the analyses of categorical indices, "relative benefit", a measurement corresponding to the "relative risk" in follow-up studies, was calculated. The relative benefit was calculated by the model which one perform follow-up studies in municipalities with high ratios of PHNs and those with low ratios of PHNs and observe whether or not each categorical index was achieved. In other words, the number of times higher the probability of having "yes" for the achievement of each index over a probability of "no" was calculated for municipalities with the high ratios of PHNs compared with municipalities with the low ratios of PHNs. (see the following formula)

\begin{tabular}{ccccc}
\hline & \multicolumn{4}{c}{ Achievement } \\
& & Yes (High) & No (Low) \\
\hline \multirow{2}{*}{ Ratio of PHNs } & High & $\mathrm{a}$ & $\mathrm{b}$ & $\mathrm{a}+\mathrm{b}$ \\
& Low & $\mathrm{c}$ & $\mathrm{d}$ & $\mathrm{c}+\mathrm{d}$ \\
\hline
\end{tabular}

Relative benefit $=\frac{a}{a+b} / \frac{c}{c+d}$

\section{RESULTS}

\section{Association between the ratios of PHNs and quanti-} tative indices

The correlation coefficients and regression coefficients between the ratios of PHNs and quantitative indices are shown in Table 2. Strong correlations are observed with the participation rates and other program achievement.

The correlation coefficients for participation rates to stomach cancer examination was 0.63 , which was the highest among all indices. The second highest was for participation rates to rehabilitation programs. Those for health counseling, health education, and basic health examination were $0.59,0.54$, and 0.50 , respectively. For cervical cancer examination it was 0.47 .

The correlation coefficients with SMRs were not so high as those with the participation rates. The correlation coefficient for SMRs of malignant neoplasms was negative,

Table 2. Correlation and regression coefficients between the ratios of PHNs and quantitative indices.

\begin{tabular}{lcccc}
\hline & $\mathrm{n}$ & $\begin{array}{c}\text { Correlation } \\
\text { Coefficient }\end{array}$ & $\mathrm{a}$ Regression Coefficient & $\mathrm{b}$ \\
\hline Basic Examination & 2,720 & $0.50^{* *}$ & 1.218 & 0.484 \\
Stomach Examination & 2,720 & $0.63^{* *}$ & 0.859 & 0.681 \\
Cervical Examination & 2,720 & $0.47^{* *}$ & 0.963 & 0.431 \\
\hline Health Education & 2,715 & $0.54^{* *}$ & 1.098 & 1.164 \\
Health Counselling & 2,714 & $0.59^{* *}$ & 1.104 & 1.238 \\
Rehabilitation & 1,722 & $0.62^{* *}$ & -0.889 & 1.300 \\
\hline SMR of Malignant & 2,720 & $-0.22^{* *}$ & 1.987 & -0.059 \\
SMR of CVDs & 2,720 & $0.10^{* *}$ & 2.007 & 0.039 \\
\hline
\end{tabular}

Notes: Regression Equation $\log ($ Index $)=a+b \cdot \log$ (Ratio of PHNs)

**: $\mathrm{p}<0.01 *:<0.05$ ns : not significant 


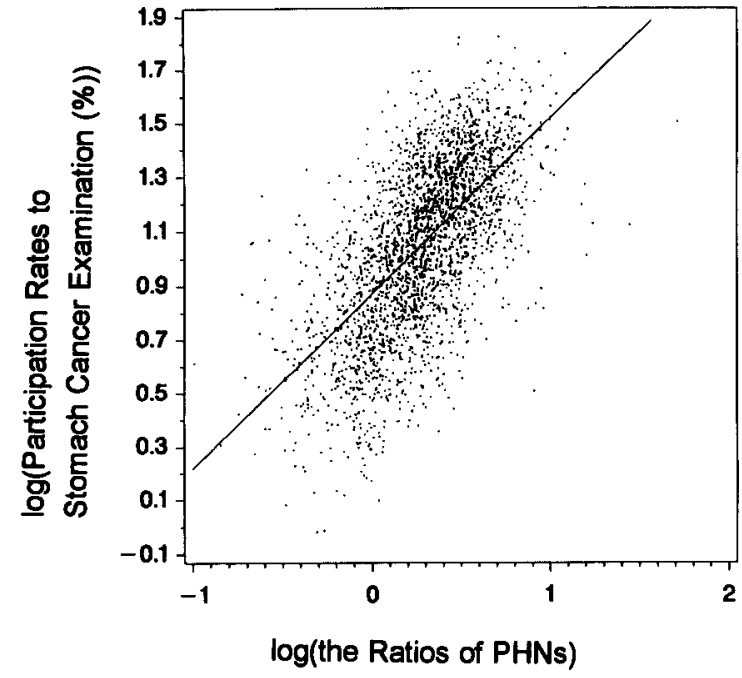

Figure 1. Relationship between the ratios of PHNs and participation rates to stomach cancer examination.

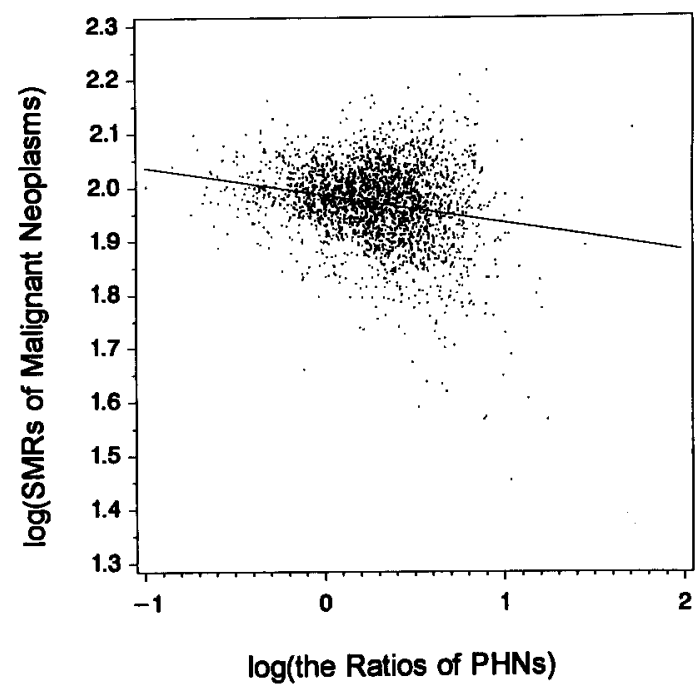

Figure 2. Relationship between the ratios of PHNs and SMRs of malignant neoplasms.

Table 3. Correlation coefficients between the ratios of PHNs and quantitative indices stratified by population size and ratio of physicians.

a. stratified by population size

\begin{tabular}{lcccccc}
\hline \multirow{2}{*}{ Population Size } & \multicolumn{3}{c}{$<10,000$} & \multicolumn{2}{c}{$10,000-49,999$} & \multicolumn{2}{c}{$50,000+$} \\
\cline { 2 - 7 } & $\mathrm{n}$ & $\begin{array}{c}\text { Correlation } \\
\text { Coefficient }\end{array}$ & $\mathrm{n}$ & $\begin{array}{c}\text { Correlation } \\
\text { Coefficient }\end{array}$ & $\mathrm{n}$ & $\begin{array}{c}\text { Correlation } \\
\text { Coefficient }\end{array}$ \\
\hline Basic Examination & 1,145 & $0.23^{* *}$ & 1,159 & $0.32^{* *}$ & 416 & $0.26^{* *}$ \\
Stomach Examination & 1,145 & $0.35^{* *}$ & 1,159 & $0.44^{* *}$ & 416 & $0.38^{* *}$ \\
Cervical Examination & 1,145 & $0.33^{* *}$ & 1,159 & $0.30^{* *}$ & 416 & $0.14^{* *}$ \\
\hline Health Education & 1,141 & $0.26^{* *}$ & 1,158 & $0.20^{* *}$ & 416 & $0.03 \mathrm{~ns}$ \\
Health Counselling & 1,140 & $0.30^{* *}$ & 1,158 & $0.21^{* *}$ & 416 & $0.10^{*}$ \\
Rehabilitation & 729 & $0.30^{* *}$ & 734 & $0.25^{* *}$ & 259 & $0.17^{* *}$ \\
\hline SMR of Malignant & 1,145 & $-0.12^{* *}$ & 1,159 & $-0.01 \mathrm{~ns}$ & 416 & $-0.11^{*}$ \\
SMR of CVDs & 1,145 & $-0.05 \mathrm{~ns}$ & 1,159 & $0.20^{* *}$ & 416 & $0.37^{* *}$ \\
\hline
\end{tabular}

b. stratified by ratio of physicians

\begin{tabular}{lcccc}
\hline \multirow{2}{*}{ Ratio of Physicians } & \multicolumn{2}{c}{$\begin{array}{c}<\text { per } \\
\text { population } 10,000\end{array}$} & \multicolumn{2}{c}{$\begin{array}{c}1+\text { per } \\
\text { population } 10,000\end{array}$} \\
\cline { 2 - 5 } & $\mathrm{n}$ & $\begin{array}{c}\text { Correlation } \\
\text { Coefficient }\end{array}$ & $\mathrm{n}$ & $\begin{array}{c}\text { Correlation } \\
\text { Coefficient }\end{array}$ \\
\cline { 2 - 5 } Basic Examination & 1,849 & $0.45^{* *}$ & 871 & $0.46^{* *}$ \\
Stomach Examination & 1,849 & $0.59^{* *}$ & 871 & $0.62^{* *}$ \\
Cervical Examination & 1,849 & $0.44^{* *}$ & 871 & $0.44^{* *}$ \\
\hline Health Education & 1,845 & $0.47^{* *}$ & 870 & $0.51^{* *}$ \\
Health Counselling & 1,844 & $0.52^{* *}$ & 870 & $0.57^{* *}$ \\
Rehabilitation & 1,180 & $0.56^{* *}$ & 542 & $0.58^{* *}$ \\
\hline SMR of Malignant & 1,849 & $-0.16^{* *}$ & 871 & $-0.30^{* *}$ \\
SMR of CVDs & 1,849 & $0.02 \mathrm{~ns}$ & 871 & $0.12^{* *}$ \\
\hline
\end{tabular}

${ }^{* *}: \mathrm{p}<0.01{ }^{*}: \mathrm{p}<0.05$ ns : not significant 
whereas that of cerebro-vascular diseases was positive.

As an example of the association with quantitative indices, a scatter diagram between the ratios of PHNs and participation rates to stomach cancer examination is shown in Fig. 1. In addition to the strong correlation, it is evident that the ratios of PHNs increase according to the achievement.

A scatter diagram for SMRs of malignant neoplasms is shown in Fig. 2. Negative and weak correlation was observed.

Correlation coefficients stratified by population size and ratio of physicians were presented in Table 3. Although the overall correlation coefficients were lower than those before stratification, they were still high and significant.

Correlation coefficients in 10,000-49,999 population are the highest. In that class, the correlation coefficients for participation rates to various examinations were over 0.3 . In the class $<10,000$ population, the correlation coefficients for health examinations and other health programs were over 0.2 . In the class $50,000+$ population, correlation coefficients were comparatively low; nevertheless, those for basic health examination and stomach cancer examination were over 0.2 and significant. In the classes of $10,000-49,999$ and $50,000+$ population, the correlation coefficients for SMRs of cerebro-vascular diseases were more than 0.2 .

For ratio of physicians, those in the class of $1+$ are higher than those in the class of $<1$. Correlation coefficients for health examinations and other health programs were over 0.4. That for SMRs of malignant neoplasms in the class of $1+$ was -0.30 .
2. Association between the ratios of PHNs and categorical indices

The relative benefits observed are shown in Table 4. Relative benefits which were higher than 2 were obtained for tracking of non-examinees, registration of stroke patients, activities of local community organizations and participation rates of various health examinations. In particular, the relative benefit for participation rates to stomach cancer examination was 4.09 , and that to cervical cancer examination was 3.30 .

Relative benefits stratified by the population size and ratio of physicians were shown in Table 5. Although the overall relative benefits were smaller than those before stratification, those were over 2 for tracking of nonexaminees, registration of stroke patients, activities of local community organizations, participation rates to health examinations, health education, and rehabilitation programs in some classes.

For the population size of $50,000+$, the relative benefit neither could be calculated nor there was a significant difference, because there was no or few municipalities which has both high ratios of PHNs and enough achievement.

The relative benefits for registration of stroke patients, activities of local community organizations, and participation rates to various health examinations were very high in the class of 10,000-49,999 population. In particular, those to stomach cancer examination and cervical cancer examination were 3.13 and 3.16 , respectively. In the class $<10,000$ population, the relative benefits for registration of stroke patients and activities of local community organizations were 2.20 and 2.53 , respectively.

For ratio of physicians, the indices for tracking of

Table 4. Relative benefits of categorical indices.

\begin{tabular}{lrrrrr}
\hline \multicolumn{1}{c}{ Indices } & $\mathrm{a}$ & $\mathrm{b}$ & $\mathrm{c}$ & $\mathrm{d}$ & \multicolumn{1}{c}{ Relative Benefit } \\
\hline Non-Examinees & 182 & 1,168 & 74 & 1,366 & $2.62^{* *}$ \\
Detailed Examination & 684 & 666 & 486 & 959 & $1.51^{* *}$ \\
Individual Invitation & 1,188 & 163 & 1,109 & 337 & $1.15^{* *}$ \\
\hline Buses to Rehabilitation & 577 & 227 & 422 & 409 & $1.41^{* *}$ \\
Registration of Stroke & 345 & 940 & 149 & 1,256 & $2.53^{* *}$ \\
Local Organization & 1,174 & 175 & 1,002 & 442 & $2.38^{* *}$ \\
\hline Basic Examination & 538 & 815 & 212 & 1,235 & $2.71^{* *}$ \\
Stomach Examination & 467 & 886 & 122 & 1,325 & $4.09^{* *}$ \\
Cervical Examination & 244 & 1,109 & 79 & 1,368 & $3.30^{* *}$ \\
\hline Health Education & 1,037 & 314 & 575 & 870 & $1.93^{* *}$ \\
Health Counselling & 1,131 & 220 & 652 & 793 & $1.86^{* *}$ \\
Rehabilitation & 821 & 530 & 471 & 973 & $1.86^{* *}$ \\
\hline SMR of Malignant & 427 & 926 & 524 & 923 & $0.87^{* *}$ \\
SMR of CVDs & 799 & 554 & 756 & 691 & $1.13^{* *}$ \\
\hline
\end{tabular}

**: $:$ < $0.01 *: p<0.05$ ns : not significant

Relative Benefit : a measurement corresponding to the "relative risk"in follow up studies

$a, b, c$, and $d$ : numbers of municipalities (see the text) 
Table 5. Relative benefits stratified by population size and ratio of physicians.

a. stratified by population size

\begin{tabular}{|c|c|c|c|c|c|c|}
\hline \multirow[b]{2}{*}{ Population Size } & \multicolumn{2}{|c|}{$<10,000$} & \multicolumn{2}{|c|}{$10,000-49,999$} & \multicolumn{2}{|c|}{$50,000+$} \\
\hline & n & $\begin{array}{c}\text { Relative } \\
\text { Benefit }\end{array}$ & $\mathrm{n}$ & $\begin{array}{c}\text { Relative } \\
\text { Benefit }\end{array}$ & $\mathbf{n}$ & $\begin{array}{l}\text { Relative } \\
\text { Benefit }\end{array}$ \\
\hline Non-Examinees & 1,215 & $1.46 \mathrm{~ns}$ & 1,159 & $1.90^{* *}$ & 416 & - \\
\hline Detailed Examinations & 1,218 & $1.30^{* *}$ & 1,163 & $1.38^{* *}$ & 414 & $0.97 \mathrm{~ns}$ \\
\hline Individual Invitation & 1,219 & $1.15^{* *}$ & 1,162 & $1.14^{* *}$ & 416 & $0.66 \mathrm{~ns}$ \\
\hline Buses to Rehabilitation & 643 & $1.10 \mathrm{~ns}$ & 687 & $1.18^{* *}$ & 305 & $1.28 \mathrm{~ns}$ \\
\hline Registration of Stroke & 1,167 & $2.20^{* *}$ & 1,114 & $2.47^{* *}$ & 409 & $3.49 \mathrm{~ns}$ \\
\hline Local Organization & 1,218 & $2.53^{* *}$ & 1,161 & $2.75^{* *}$ & 414 & - \\
\hline Basic Examination & 1,221 & $1.17 \mathrm{~ns}$ & 1,163 & $2.10^{* *}$ & 416 & - \\
\hline Stomach Examination & 1,221 & $1.41^{* *}$ & 1,163 & $3.13^{* *}$ & 416 & - \\
\hline Cervical Examination & 1,221 & $1.07 \mathrm{~ns}$ & 1,163 & $3.16^{* *}$ & 416 & - \\
\hline Health Education & 1,217 & $1.01 \mathrm{~ns}$ & 1,163 & $1.38^{* *}$ & 416 & - \\
\hline Health Counselling & 1,217 & $1.00 \mathrm{~ns}$ & 1,163 & $1.37^{* *}$ & 416 & - \\
\hline Rehabilitation & 1,216 & $1.14^{*}$ & 1,163 & $1.39 * *$ & 416 & - \\
\hline SMR of Malignant & 1,221 & $1.06 \mathrm{~ns}$ & 1,163 & $1.08 \mathrm{~ns}$ & 416 & $1.07 \mathrm{~ns}$ \\
\hline SMR of CVDs & 1,221 & $1.17^{*}$ & 1,163 & $1.16^{* *}$ & 416 & $1.21 \mathrm{~ns}$ \\
\hline
\end{tabular}

b. stratified by ratio of physicians

\begin{tabular}{lcccc}
\hline \multirow{2}{*}{ Ratio of Physicians } & \multicolumn{2}{c}{$\begin{array}{c}<1 \text { per } \\
\text { population } 10,000\end{array}$} & \multicolumn{2}{c}{$\begin{array}{c}1+\text { per } \\
\text { population } 10,000\end{array}$} \\
\cline { 2 - 5 } & $\mathrm{n}$ & $\begin{array}{c}\text { Relative } \\
\text { Benefit }\end{array}$ & $\mathrm{n}$ & $\begin{array}{c}\text { Relative } \\
\text { Benefit }\end{array}$ \\
\hline Non-Examinees & 1,907 & $2.52^{* *}$ & 883 & $2.12^{* *}$ \\
Detailed Examinations & 1,912 & $1.42^{* *}$ & 883 & $1.66^{* *}$ \\
Individual Invitation & 1,912 & $1.16^{* *}$ & 885 & $1.11^{* *}$ \\
\hline Buses to Rehabilitation & 1,079 & $1.31^{* *}$ & 556 & $1.41^{* *}$ \\
Registration of Stroke & 1,833 & $2.53^{* *}$ & 857 & $2.71^{* *}$ \\
Local Organization & 1911 & $2.36^{* *}$ & 882 & $2.25^{* *}$ \\
\hline Basic Examination & 1,915 & $2.19^{* *}$ & 885 & $3.32^{* *}$ \\
Stomach Examination & 1,915 & $3.02^{* *}$ & 885 & $6.92^{* *}$ \\
Cervical Examination & 1,915 & $2.74^{* *}$ & 885 & $3.82^{* *}$ \\
\hline Health Education & 1,913 & $1.54^{* *}$ & 883 & $2.72^{* *}$ \\
Health Counselling & 1,913 & $1.47^{* *}$ & 883 & $2.69^{* *}$ \\
Rehabilitation & 1,912 & $1.50^{* *}$ & 883 & $2.61^{* *}$ \\
\hline SMR of Malignant & 1,915 & $0.95 \mathrm{~ns}$ & 885 & $0.74^{* *}$ \\
SMR of CVDs & 1,915 & $1.06 \mathrm{~ns}$ & 885 & $1.07 \mathrm{~ns}$ \\
\hline
\end{tabular}

**: $\mathrm{p}<0.01 *: \mathrm{p}<0.05 \mathrm{~ns}$ : not significant

Relative Benefit : a measurement corresponding to the "relative risk" in follow up studies

non-examinees, registration of stroke patients, activities of local community organizations, and participation rates to various health examination showed high relative benefit in both classes. Moreover, in the class of $1+$ physicians, the participation rates to health education, health counseling, and rehabilitation programs showed high relative benefits. In particular, the relative benefit for the participation rates to stomach cancer examination in the class of $1+$ physicians was 6.92 .

\section{DISCUSSION}

In the current study, I have shown that the numbers of PHNs in municipalities relate to the health services conducted by the municipal governments. Because of the large sample size, the results are reliable.

Correlation coefficients between the ratios of PHNs and participation rates to various aspects of health care programs, particularly to stomach cancer examination were 
high. This suggested that the increase of participation rates to health examination programs is related to the activities of PHNs in municipalities.

The high correlation coefficient for participation rates to rehabilitation programs may reflect the fact that PHNs play a major role in the rehabilitation programs which municipal governments provide by the law. Rehabilitation programs should be performed by physical therapists for physical renovation such as enlargement in range of movement. Nevertheless, rehabilitation programs performed by PHNs in municipalities may have other meanings, such as making friends.

The SMRs of malignant neoplasms tended to have negative correlation coefficients with the ratios of PHNs, besides participation rates to stomach and cervical cancer examinations had positive correlation. Activities of PHNs should contribute high participation rates to cancer examinations, and may cause low SMRs of malignant neoplasms through the screening of target cancers.

On the other hand, the correlation coefficient with SMRs of cerebro-vascular diseases was positive. Municipalities with high incidence of cerebro-vascular diseases might actively strive to provide the adequate numbers of PHNs.

Using regression models estimated, I estimate the ratios of PHNs to achieve the target participation rates of the Second 5-year Plan organized by the Ministry of Health and Welfare, the Japanese Government. It is estimated that 1.96 PHNs, 1.97 PHNs, and 2.72 PHNs per 10,000 population are required to achieve $35 \%$ of participation rate for the basic health examination, $21 \%$ for stomach cancer examination, and $24.8 \%$ for cervical cancer examination, respectively.

The relative benefit for activities of local community organizations and the ratios of PHNs was extremely high. Furthermore, the relative benefit for tracking of nonexaminees and that of non-respondents to examinees required taking detailed examinations, individual invitation to receive examinations, and registration of stroke patients was also high. These indices can be improved by effective data processing systems, and that may be provided by the adequate numbers of PHNs.

In addition, there was a significant relation with buses providing transportation to rehabilitation programs. The positive attitude of municipalities towards health care was probably reflected in providing adequate facilities as well as the numbers of PHNs. Moreover, PHNs may express their opinion about health care budgets in some municipalities.

The fact that correlation coefficients and relative benefits became lower by stratification analysis by population size and the ratio of physicians, in many of the instances, demonstrates interactions among stratified indices. However, even after stratification, some indices showed considerably strong correlations.
Municipalities with population size of $10,000-49,999$ tended to have higher relative benefit than those with population size of $<10,000$ and with $50,000+$. In consideration of the cause of this phenomenon, the achievement of health care programs may be based various and unique factors such as geographical locations or special ideas of mayors in the municipalities with population sizes of $<10,000$ and those of $50,000+$. Besides, for municipalities with $10,000-49,999$ population, the numbers of PHNs may be more important factor.

The association with various participation rates was higher for municipalities with $1+$ in ratio of physicians than those with $<1$. Rather than an independent effect of the numbers of PHNs, a synergistic effect with PHNs and physicians appears to exist. In other words, in municipalities with many physicians, the activities of PHNs on the health care programs might be well supported by the physicians. In addition, interactions between ratio of physicians and population sizes should also be considered.

In summary, my observations about the relationships between the numbers of PHNs and the health care programs in municipalities have shown the following results: (1) There are strong correlations between the ratios of PHNs and program achievement and execution systems. The higher the number of PHNs, the easier it is to organize systems for program execution and to increase the achievement. And (2) using regression models I estimated that 1.96-2.72 PHNs per 10,000 population are required to achieve the target participation rates organized by the Japanese Government. In municipalities where the numbers of PHNs is small and achievement of their programs are unsatisfactory in particular, it is suggested that they should increase the numbers of PHNs to implement effective programs.

\section{ACKNOWLEDGMENTS}

I wishes to thank Drs. Hiroshi Yanagawa, Atsuhiko Tsukuda, Kiyomi Sakata, and Yosikazu Nakamura, and other staff of the Department of Public Health, Jichi Medical School and Institute of Public Health for their helpful and important suggestions.

\section{REFERENCES}

1. Health and Welfare Statistics Association. The Trend of National Health. Health and Welfare Statistics Association, Tokyo, 1991: 17 (in Japanese).

2. Ministry of Home Affairs Administration Bureau Promotion Section. All Japan Municipal Governments List. Daiichi Houki, Tokyo, 1991 : 4 (in Japanese).

3. Sakata K. A Study on Health Examination Services under the Health Service Law for the Aged-Multiple logistic regression analysis of service methods and the service - acceptance rate - . Jpn J Hyg, 1991; 46: 715-723 (in Japanese with English abstract). 
4. Tatara K, Shinsho F, Kuroda K, Nakabayashi K, Yuzawa F, Hashimoto $M$. Correlation between receiving rate of health services and number of public health nurses per number of residents by type of health center. Nihon Koshu Eisei Zasshi 1988; 35: 115-123 (in Japanese with English abstract).

5. Tsukuda A. The Investigation Report about Health Care Programs for the Aged in Municipal Governments. The study group on health care programs in the secondary medical service areas (Department of Public Health, Jichi Medical School), Tochigi, 1992 (in Japanese).

6. Statistical Information Division the Secretariat of the Ministry of Health and Welfare. Wide-area Information-exchange System for Health and welfare [WISH] Manual for Regional Health Planning Support System. Tokyo, 1991 (in Japanese).

7. SAS Institute Inc. SAS procedure reference guide Release 6.03 Edition. SAS Institute, Vary, NC, 1990.
8. SAS Institute Inc. SAS/STAT ${ }^{\mathrm{TM}}$ user's guide Release 6.03 Edition. SAS Institute, Vary, NC, 1991.

9. SAS Institute Inc. SAS/GRAPH ${ }^{\oplus}$ reference guide Release 6.03 Edition. SAS Institute, Vary, NC, 1991.

10. Aged Health Care Section, Ministry of Health and Welfare. Manual on new Health Care Programs-Outline of the Second 5-year Plan of the Health Programs for the Aged. Sinkikaku Publisher, Tokyo, 1986 (in Japanese).

11. Statistical Information Division, the Secretariat of the Ministry of Health and Welfare. Report 1989 of the Health Care Programs for the Aged. Health and Welfare Statistics Association, Tokyo, 1991 (in Japanese).

12. Statistical Bureau, Prime Minister's Office: Census 1985 vol. 2 primary basic analysis No. 1 whole country volume. Japan Statistics Association, Tokyo, 1986. 